Article

\title{
The Interactions between Ciprofloxacin and Parenteral Nutrition Admixtures
}

\author{
Aleksandra Gostyńska, Maciej Stawny *(D, Katarzyna Dettlaff ${ }^{\mathbb{D}}$ and Anna Jelińska \\ Department of Pharmaceutical Chemistry, Poznan University of Medical Sciences, 6 Grunwaldzka, \\ 60-780 Poznań, Poland; gostynska.aleksandra@spsk2.pl (A.G.); dettlaff@ump.edu.pl (K.D.); \\ ajelinsk@ump.edu.pl (A.J.) \\ * Correspondence: mstawny@ump.edu.pl; Tel.: +48-618546646
}

Received: 30 October 2019; Accepted: 20 December 2019; Published: 27 December 2019

\begin{abstract}
Background: Co-infusion of parenteral nutrition $(\mathrm{PN})$ and other drugs increases the risk of the interaction between drug and PN admixtures that can cause embolization of small blood vessels, resulting in potentially fatal consequences, including pulmonary embolism, or liver and retina vascular damage. The present study aimed to determine the compatibility between ciprofloxacin (CF) and eighteen compounded PN admixtures in order to assess the possibility of their co-administration via Y-sites. Methods: $\mathrm{CF}$ and PN admixtures were mixed at two volume ratios (1:1 and 2:1) and potential interactions were examined using visual inspection, and measurements of $\mathrm{pH}$, osmolality particle size, and zeta potential. The analyses were conducted immediately after sample preparation and after four hours of storage. Results: The compatibility tests showed that the addition of the CF to the PN admixtures did not cause any color change or sign of destabilization in the fat emulsion. However, precipitation was observed in formulations containing higher $\mathrm{CF}$ concentrations and, in the case of lower $\mathrm{CF}$ concentrations, in formulations containing magnesium and calcium ions at a molar ratio of 2:1. Conclusions: The administration of $\mathrm{CF}$ and $\mathrm{PN}$ admixtures via the Y-site should be avoided or performed only with PN admixtures for which compatibility has been confirmed and the CF concentration in samples is $1 \mathrm{mg} / \mathrm{mL}$ at a molar ratio of magnesium to calcium ions of 1:1.
\end{abstract}

Keywords: ciprofloxacin; parenteral nutrition; zeta potential; compatibility; drug interactions

\section{Introduction}

The treatment of bacterial infections is a challenge to modern medicine, as more than 50 percent of patients in intensive care units suffer from bacterial infections [1]. The mortality rate of infected patients is twice as high as for uninfected patients, and antibacterial treatment accounts for up to 40 percent of the cost of hospitalization of critically ill patients [1].

Ciprofloxacin (CF) is a broad-spectrum chemotherapeutic agent characterized by significant potency against Gram-negative bacteria and atypical pathogens. CF is often used to treat moderate to severe bacterial infections, especially those of the respiratory and urinary tracts in critically ill patients [2]. However, the overuse of $\mathrm{CF}$ has caused an increase in the drug resistance of Gram-negative bacteria, particularly Pseudomonas aeruginosa, Klebsiella pneumonia, Escherichia coli, and Acinetobacter spp. [2].

Critically ill patients often require nutritional support in the form of enteral or parenteral nutrition. Parenteral nutrition (PN) involves the intravenous supply of all necessary nutrients and frequently coexists with the infusion of other parenteral drugs. In patients with limited access to blood vessels, it is necessary to interrupt PN infusion or combine two pharmaceutical preparations (PN admixture and another parenteral drug) into one infusion using the Y-site. Such a procedure raises the risk of interaction in the pharmaceutical phase and may lead to precipitation or destabilization of the fat emulsion. Administration of two incompatible preparations in one infusion may endanger the patient's health and life, resulting in the economic consequences of treating medical complications. 
Therefore, the determination of principles for administration of drugs and PN admixtures via the Y-site is a vital aspect of clinical practice, especially in light of the reports of Taxis and Barber [3], who have shown that about a half of all intravenous preparations and infusions are administered incorrectly. Administration of incompatible preparations causes approximately 20 percent of all medical errors and constitutes almost $89 \%$ of errors in drug administration $[4,5]$.

In one of the first studies on the supply of drugs with PN admixture via the Y-site, the volume ratio of both preparations during infusion was determined. The drug-PN admixture ratio obtained at that time was $1: 1(v / v)$, to be reproduced in subsequent studies on parenteral drug compatibility [6]. However, when two simultaneous infusions are administered, e.g., a 12-24 h PN infusion and a 15-60 min infusion of another intravenous drug, this proportion may differ significantly. In this case, the volume ratio of the drug to the $\mathrm{PN}$ admixture should be calculated considering the infusion rate of both preparations [7] or an appropriate drug-PN admixture combination should be obtained, simulating the supply of both preparations by using an infusion pump [8].

PN admixtures are the most complex drugs used in modern medicine. Up to 50 different substances are mixed together in one package, which raises the possibility of physicochemical interactions $[9,10]$. Administering a PN admixture simultaneously with another infusion drug or adding a drug to the PN admixture carries a high risk of physical or chemical incompatibility.

In the case of supply using the Y-site, chemical incompatibilities are considered less significant due to the short time that both preparations are in contact (1-2 min) [11]. However, when drugs are added to the PN admixture, any resulting chemical incompatibility can significantly affect the treatment outcome. Then it is necessary to confirm the chemical stability of the added substance. A decrease in the drug content by more than $10 \%$ during preparation, storage, and administration disqualifies its addition to the PN admixture [12]. Regardless of the manner in which the PN admixture and the drug are supplied (simultaneous supply via the Y-site or adding the drug to the PN admixture), physical incompatibilities may occur manifested as precipitation, lipid emulsion destabilization, or color change $[9,10]$. The formation of lipid emulsion droplets larger than $500 \mathrm{~nm}$ in diameter or precipitation of insoluble sediment can cause embolization of small blood vessels, leading to potentially fatal effects, such as pulmonary embolism or capillary damage of the liver or the eye retina [13-17]. The risk of physical incompatibility is associated with $\mathrm{pH}$ differences between preparations, the concentration of the drug added and PN admixture ingredients, the temperature and light exposure during storage and administration. PN admixture is an oil-in-water emulsion with a $\mathrm{pH}$ of 5.5-7.5, stabilized by egg phospholipids [18]. Lowering the $\mathrm{pH}$ below 5.5 may lead to destabilization of the emulsion as a result of a change in charge on the micelle surface and, consequently, phase separation of the system. High electrolyte concentrations, especially divalent and trivalent cations, may also affect the surface charge of lipid droplets destabilizing the oil-in-water system [19].

The aim of the study was to determine interaction between CF and PN admixtures when infused simultaneously using the Y-site. In order to find the relationship between the composition of PN admixture and CF compatibility, 18 different PN admixture formulations were used in the study, which differed in the lipid emulsion type and the content and molar ratio of electrolytes. The $\mathrm{CF}$ and the PN admixtures were mixing together at two volume ratios 1:1 and 1:2, which corresponded to CF concentrations of 1.33 and $1.00 \mathrm{mg} / \mathrm{mL}$, respectively. In order to determine possible interactions, measurements were carried out of $\mathrm{pH}$, osmolality, zeta potential, and mean droplet diameter (MDD) of lipid emulsion.

\section{Materials and Methods}

\subsection{Composition of PN Admixtures}

Eighteen formulations of PN admixtures were selected for the study differing in the type of lipid source and the content of electrolytes (Table 1). The composition of the PN admixtures was based on literature recommendations for adult hospitalized patients. Two different types of lipid emulsion were used. The PN admixtures containing Lipofundin ${ }^{\circledR}$ MCT/LCT (PN1-PN13) (B. Braun Melsungen AG, 
Melsungen, Germany) consisted of long-chain triglycerides (LCT) and medium-chain triglycerides (MCT). The PN admixtures containing Smoflipid (PN14-PN18) (Fresenius Kabi AB, Upsala, Sweden) were based on a lipid emulsion consisting of MCT, LCT, olive oil), and triglycerides of omega-3 acids.

\subsection{Preparation of $P N$ Admixtures and CF-PN Samples}

The PN admixtures were prepared in aseptically under a laminar-flow air hood, using a Pinnacle B. Braun automatic compounder (B. Braun Melsungen AG, Melsungen, Germany) ensuring high-precision dosing. The final volume of $1800 \mathrm{~mL}$ was packaged in an ethylene-vinyl acetate (EVA) bag (B. Braun Melsungen AG, Melsungen, Germany).

The samples were prepared by mixing the PN admixtures with a CF solution for infusion (Ciprofloxacin Kabi $200 \mathrm{mg} / 100 \mathrm{~mL}$, Polpharma S.A., Starograd Gdański, Poland) at ratios based on infusion rates for both medications. The infusion time for the CF $(0.5 \mathrm{~h})$ was specified in the summary of product characteristics. The infusion time for the PN admixtures $(20 \mathrm{~h})$ was based on clinical practice. The infusion rates were calculated on the basis of the infusion times and the drug volumes (100 and $1800 \mathrm{~mL}$ for the $\mathrm{CF}$ and the PN admixtures, respectively). The volume ratios of the $\mathrm{CF}$ and the PN admixtures in the infusion line $(1: 1 ; 1: 2)$ were obtained by dividing the drug infusion rate by the infusion rate of the PN admixture. The concentrations of the CF in the CF-PN samples at the volume ratios $1: 1$ and $1: 2$ were $1.33 \mathrm{mg} / \mathrm{mL}$ and $1.00 \mathrm{mg} / \mathrm{mL}$, respectively. Each sample was examined immediately after preparation and after four hours of storage at $25 \pm 1{ }^{\circ} \mathrm{C}$. We prepared three independent samples for each combination of CF-PN admixtures in each volume ratios.

\subsection{Visual Inspection}

In accordance with the European Pharmacopoeia [20], all PN admixtures were visually assessed for the presence of visible particles and/or color change. Visual inspection was performed against a black-and-white contrast background by two observers. Following the pharmacopeial requirements for intravenous lipid emulsions, to consider PN admixtures as compatible with $\mathrm{CF}$, they must be practically free from visible particles, and no precipitation can be detected by either observer upon visual inspection.

\section{4. $p H$ Evaluation}

The $\mathrm{pH}$ was measured at room temperature, using Mettler Toledo Seven Compact $\mathrm{pH} /$ ion S220 ${ }^{\circledR}$ pH-meter (Mettler Toledo, Columbus, OH, USA). Each sample was measured in triplicate, and the results were expressed as average \pm standard deviation.

\subsection{Determination of MDD of Lipid Emulsion and Zeta Potential}

The MDD of lipid emulsion and zeta potential $(\xi)$ of PN admixtures were measured at $25{ }^{\circ} \mathrm{C}$, using a Zetasizer Nano ZS (Malvern Instruments, Malvern, UK) by dynamic light scattering (DLS) and laser Doppler velocimetry respectively. The sample preparation, particles size, and zeta potential determination were performed according to the methodology described in our previous work [21]. The results of droplet diameter measurements were presented as follows: MDD (intensity weighted mean droplet diameter). All the measurements were performed in triplicate, and the results were expressed as average \pm standard deviation.

To consider PN admixtures compatible with $\mathrm{CF}$, the following criteria must be met: the size of lipid droplets expressed as intensity-weighted MDD cannot exceed the pharmacopeial limit of $500 \mathrm{~nm}$. This criterion was set for the US pharmacopeia method I for the determination of the mean droplet size of lipid injectable emulsions [22]. 
Table 1. Composition and characteristic of PN admixtures.

\begin{tabular}{|c|c|c|c|c|c|c|c|c|c|c|c|c|c|c|c|c|c|c|c|}
\hline Ingredient/Parameter & Unit & PN1 & PN2 & PN3 & PN4 & PN5 & PN6 & PN7 & PN8 & PN9 & PN10 & PN11 & PN12 & PN13 & PN14 & PN15 & PN16 & PN17 & PN18 \\
\hline Amino Acid & & 27 & 27 & 63 & 63 & 27 & 27 & 63 & 63 & 27 & 27 & 63 & 63 & 27 & 27 & 63 & 63 & 27 & 27 \\
\hline Glucose & & 180 & 180 & 180 & 180 & 180 & 180 & 180 & 180 & 180 & 180 & 180 & 180 & 180 & 180 & 180 & 180 & 180 & 180 \\
\hline Lipid Emulsion & $\mathrm{g}$ & $9^{a}$ & $45^{\text {a }}$ & $9^{a}$ & $45^{\mathrm{a}}$ & $9^{a}$ & $45^{\mathrm{a}}$ & $9^{a}$ & $45^{\mathrm{a}}$ & $9^{\mathrm{a}}$ & $45^{\mathrm{a}}$ & $9^{a}$ & $45^{\mathrm{a}}$ & $9^{b}$ & $45^{b}$ & $9^{b}$ & $45^{\mathrm{b}}$ & $45^{\mathrm{b}}$ & $9^{b}$ \\
\hline Water & & 893 & 713 & 549 & 369 & 928 & 748 & 583 & 403 & 966 & 789 & 611 & 434 & 894 & 714 & 549 & 369 & 748 & 928 \\
\hline Sodium & & 117 & 117 & 117 & 117 & 117 & 117 & 117 & 117 & 72 & 66 & 82 & 77 & 117 & 117 & 117 & 117 & 117 & 117 \\
\hline Potassium & & 99 & 99 & 99 & 99 & 99 & 99 & 99 & 99 & 7 & 7 & 16 & 16 & 99 & 99 & 99 & 99 & 99 & 99 \\
\hline Magnesium & $\mathrm{mmol}$ & 7 & 7 & 7 & 7 & 2 & 2 & 2 & 2 & 7 & 7 & 7 & 7 & 7 & 7 & 7 & 7 & 2 & 2 \\
\hline Calcium & & 7 & 7 & 7 & 7 & 1 & 1 & 1 & 1 & 7 & 7 & 7 & 7 & 7 & 7 & 7 & 7 & 1 & 1 \\
\hline Phosphate & & 56 & 56 & 89 & 89 & 56 & 56 & 56 & 56 & 89 & 89 & 56 & 56 & 56 & 56 & 89 & 89 & 56 & 56 \\
\hline Total Energy & kcal & 909 & 1233 & 1053 & 1377 & 909 & 1233 & 2021 & 1697 & 2567 & 2248 & 2072 & 1753 & 900 & 1233 & 1233 & 1377 & 1233 & 909 \\
\hline $\begin{array}{l}\text { Theoretical } \\
\text { Osmolarity }\end{array}$ & $\mathrm{mOsm} / \mathrm{L}$ & 919 & 959 & 1093 & 1134 & 919 & 959 & 1094 & 1134 & 757 & 791 & 956 & 989 & 918 & 956 & 1093 & 1131 & 956 & 918 \\
\hline Total Volume & $\mathrm{mL}$ & 1800 & 1800 & 1800 & 1800 & 1800 & 1800 & 1800 & 1800 & 1800 & 1800 & 1800 & 1800 & 1800 & 1800 & 1800 & 1800 & 1800 & 1800 \\
\hline
\end{tabular}




\subsection{Osmolality Determination}

The osmolality was measured at room temperature, using 800 CLG TridentMed ${ }^{\circledR}$ osmometer (TridentMed s.c., Warsaw, Poland). $100 \mu \mathrm{L}$ of CF, PN, and CF-PN admixtures was injected into the Eppendorf tube, and the tube was placed in a cooling chamber. The measurements were performed immediately (time $=0 \mathrm{~h}$ ) after samples preparation and $4 \mathrm{~h}$ later. Each sample was measured in triplicate, and the results were expressed as average \pm standard deviation.

\subsection{Fourier Transform Infrared Spectroscopy (FT-IR)}

The precipitate was filtered and dried. Then, $1 \mathrm{mg}$ of precipitate (tested sample) was micronized and mixed with $300 \mathrm{mg}$ of $\mathrm{KBr}$ to produce tablets $(1.3 \mathrm{~cm} \times 0.1 \mathrm{~cm})$. The reference spectrum was obtained by using the same tableting method by mixing $1 \mathrm{mg}$ of CF (Sigma Aldrich, Saint Louis, MO, USA) with $300 \mathrm{mg}$ of KBr. FT-IR spectra were collected on an IRAffinity-IS Fourier Transform Infrared Spectrophotometer (Shimadzu, Kyoto, Japan) instrument in the range of $400-4000 \mathrm{~cm}^{-1}$, with a resolution of $4.0 \mathrm{~cm}^{-1}$ and 40 scans. The identity of CF was confirmed by comparing the spectrum of precipitate with the spectrum of the reference sample and by calculating the purity factor. Purity $(P)$ is a factor that indicates the degree of matching between two spectra. This factor is given by the least-squares-fit coefficient that is calculated for every intensity pair of the two spectra being compared. $P$ factor can be calculated by using the following formula:

$$
P=\frac{\sum_{i}^{n}\left(s_{i}-s\right) \times\left(r_{i}-r\right)}{\sqrt{\sum_{i}^{n}\left(s_{i}-s\right)^{2} \times \sum_{i}^{n}(r-r)^{2}}},
$$

where $s_{i}$ and $r_{i}$ are the respective intensities for the same horizontal coordinate value, and $n$ is the number of data points; $s$ and $r$ are the average intensities of each spectrum.

The purity value is between 0 and 1 , where 0 indicates no identity between the two spectra, and 1 indicates that the two spectra are identical.

\subsection{Statistical Analysis}

The data were analyzed by using Statistica 12 software (StatSoft). Two-way analyses of variance (ANOVAs) was used to determine the statistical significance between samples. The a priori level of significance was $p<0.05$. In the case of a major effect or interaction, significant differences between the tested TPN admixtures (with drugs) and the reference samples under the study conditions were identified using Tukey's HSD post hoc tests.

\section{Results}

An ANOVA analysis of the main effects for the CF and the PN admixtures showed a statistically significant $(p<0.05)$ effect of the CF and PN admixture formulations on the $\mathrm{pH}$, osmolality, zeta potential, and MDD of the lipid emulsion. A statistically significant $(p<0.05)$ effect of storage time on all parameters was also observed, with the exception of osmolality.

The $\mathrm{pH}$ of the PN admixtures (PN1-PN18) ranged from 6.34 to 6.72 (Table 2). The addition of the $\mathrm{CF}$ caused a significant decrease in the $\mathrm{pH}$ of all formulations. The $\mathrm{pH}$ of CF-(PN1-PN18) admixtures ranged from 5.90 to 6.33. The osmolality of all $\mathrm{PN}$ admixtures ranged from $848 \pm 1 \mathrm{mOsm} / \mathrm{kg}$ of $\mathrm{H}_{2} \mathrm{O}$ to $1281 \pm 3 \mathrm{mOsm} / \mathrm{kg}$ of $\mathrm{H}_{2} \mathrm{O}$ and decreased significantly $(p<0.05)$ after adding the $\mathrm{CF}$ and ranged from $441 \pm 1 \mathrm{mOsm} / \mathrm{kg}$ of $\mathrm{H}_{2} \mathrm{O}$ to $730 \pm 5 \mathrm{mOsm} / \mathrm{kg}$ of $\mathrm{H}_{2} \mathrm{O}$ (Table 3). 
Table 2. Results of $\mathrm{pH}$, osmolality, zeta potential, and particle size of PN admixtures.

\begin{tabular}{|c|c|c|c|c|c|c|c|c|}
\hline \multirow[t]{2}{*}{ PN Admixture } & \multicolumn{2}{|c|}{$\mathrm{pH} \pm \mathrm{SD}$} & \multicolumn{2}{|c|}{$\begin{array}{l}\text { Osmolality } \pm \text { SD } \\
\left(\mathrm{mOsm} / \mathrm{kg} \mathrm{H} \mathrm{H}_{2} \mathrm{O}\right)\end{array}$} & \multicolumn{2}{|c|}{$\begin{array}{c}\text { Zeta Potential } \pm \text { SD } \\
(\mathrm{mV})\end{array}$} & \multicolumn{2}{|c|}{$\begin{array}{l}\mathrm{MDD} \pm \mathrm{SD} \\
(\mathrm{nm})\end{array}$} \\
\hline & $0 \mathrm{~h}$ & $4 \mathrm{~h}$ & $0 \mathrm{~h}$ & $4 \mathrm{~h}$ & $0 \mathrm{~h}$ & $4 \mathrm{~h}$ & $0 \mathrm{~h}$ & $4 \mathrm{~h}$ \\
\hline PN1 & $6.61 \pm 0.01$ & $6.60 \pm 0.00$ & $996 \pm 5$ & $997 \pm 3$ & $-11.12 \pm 1.09$ & $-11.53 \pm 0.85$ & $219.7 \pm 1.9$ & $215.7 \pm 2.9$ \\
\hline PN2 & $6.60 \pm 0.00$ & $6.61 \pm 0.01$ & $1076 \pm 4$ & $1076 \pm 5$ & $-11.40 \pm 1.00$ & $-11.33 \pm 0.85$ & $220.0 \pm 1.4$ & $218.3 \pm 1.5$ \\
\hline PN3 & $6.36 \pm 0.00$ & $6.37 \pm 0.01$ & $1217 \pm 3$ & $1217 \pm 2$ & $-9.19 \pm 0.43$ & $-9.89 \pm 0.09$ & $219.2 \pm 1.1$ & $218.7 \pm 1.9$ \\
\hline PN4 & $6.34 \pm 0.01$ & $6.34 \pm 0.01$ & $1281 \pm 3$ & $1281 \pm 5$ & $-8.38 \pm 0.15$ & $-7.88 \pm 0.58$ & $220.6 \pm 1.6$ & $221.7 \pm 0.9$ \\
\hline PN5 & $6.68 \pm 0.00$ & $6.69 \pm 0.01$ & $992 \pm 3$ & $992 \pm 4$ & $-17.50 \pm 1.05$ & $-14.73 \pm 1.46$ & $216.5 \pm 2.4$ & $217.0 \pm 3.5$ \\
\hline PN6 & $6.64 \pm 0.00$ & $6.65 \pm 0.01$ & $1057 \pm 6$ & $1057 \pm 7$ & $-16.37 \pm 0.75$ & $-15.77 \pm 0.32$ & $219.4 \pm 2.6$ & $220.8 \pm 2.1$ \\
\hline PN7 & $6.42 \pm 0.01$ & $6.40 \pm 0.01$ & $1172 \pm 4$ & $1172 \pm 5$ & $-11.58 \pm 2.92$ & $-10.30 \pm 2.51$ & $222.0 \pm 1.5$ & $223.9 \pm 3.7$ \\
\hline PN8 & $6.39 \pm 0.01$ & $6.38 \pm 0.01$ & $1278 \pm 3$ & $1278 \pm 4$ & $-13.87 \pm 2.46$ & $-13.87 \pm 1.85$ & $224.7 \pm 3.6$ & $221.3 \pm 2.5$ \\
\hline PN9 & $6.72 \pm 0.01$ & $6.73 \pm 0.01$ & $848 \pm 1$ & $848 \pm 3$ & $-13.00 \pm 0.10$ & $-13.50 \pm 1.13$ & $221.0 \pm 1.0$ & $216.8 \pm 2.0$ \\
\hline PN10 & $6.71 \pm 0.01$ & $6.70 \pm 0.00$ & $900 \pm 5$ & $899 \pm 5$ & $-12.87 \pm 1.90$ & $-14.67 \pm 0.67$ & $223.4 \pm 0.4$ & $221.9 \pm 0.9$ \\
\hline PN11 & $6.43 \pm 0.01$ & $6.42 \pm 0.01$ & $1042 \pm 1$ & $1042 \pm 3$ & $-9.83 \pm 0.99$ & $-7.42 \pm 1.88$ & $220.4 \pm 1.4$ & $219.3 \pm 0.9$ \\
\hline PN12 & $6.41 \pm 0.01$ & $6.40 \pm 0.00$ & $1136 \pm 7$ & $1135 \pm 5$ & $-10.00 \pm 0.78$ & $-9.91 \pm 0.25$ & $221.8 \pm 2.1$ & $219.6 \pm 0.8$ \\
\hline PN13 & $6.62 \pm 0.01$ & $6.61 \pm 0.01$ & $994 \pm 3$ & $993 \pm 3$ & $-17.97 \pm 0.81$ & $-19.17 \pm 2.31$ & $336.7 \pm 3.6$ & $334.5 \pm 4.4$ \\
\hline PN14 & $6.63 \pm 0.00$ & $6.63 \pm 0.00$ & $1053 \pm 3$ & $1053 \pm 2$ & $-18.37 \pm 3.26$ & $-16.80 \pm 1.15$ & $335.0 \pm 1.9$ & $329.5 \pm 4.4$ \\
\hline PN15 & $6.39 \pm 0.01$ & $6.39 \pm 0.00$ & $1197 \pm 2$ & $1196 \pm 6$ & $-12.70 \pm 0.60$ & $-13.10 \pm 0.61$ & $338.8 \pm 3.4$ & $334.8 \pm 3.6$ \\
\hline PN16 & $6.37 \pm 0.01$ & $6.38 \pm 0.01$ & $1271 \pm 3$ & $1271 \pm 2$ & $-11.27 \pm 0.31$ & $-13.00 \pm 0.89$ & $330.9 \pm 4.9$ & $330.4 \pm 3.1$ \\
\hline PN17 & $6.69 \pm 0.01$ & $6.69 \pm 0.00$ & $1047 \pm 3$ & $1048 \pm 5$ & $-15.83 \pm 1.10$ & $-18.33 \pm 1.12$ & $329.0 \pm 2.8$ & $326.1 \pm 5.5$ \\
\hline PN18 & $6.69 \pm 0.00$ & $6.69 \pm 0.01$ & $979 \pm 4$ & $978 \pm 6$ & $-22.47 \pm 0.81$ & $-23.80 \pm 1.31$ & $328.6 \pm 3.2$ & $335.0 \pm 6.4$ \\
\hline
\end{tabular}


Table 3. Results of $\mathrm{pH}$, osmolality, zeta potential, and particle size of CF-PN samples.

\begin{tabular}{|c|c|c|c|c|c|c|c|c|c|}
\hline \multirow{2}{*}{$\begin{array}{c}\text { PN } \\
\text { Admixture }\end{array}$} & \multirow{2}{*}{$\begin{array}{c}\text { CF:PN } \\
\text { Volume Ratio }\end{array}$} & \multicolumn{2}{|c|}{$\mathrm{pH} \pm \mathrm{SD}$} & \multicolumn{2}{|c|}{$\begin{array}{l}\text { Osmolality } \pm \text { SD } \\
\left(\mathrm{mOsm} / \mathrm{kg} \mathrm{H}_{2} \mathrm{O}\right)\end{array}$} & \multicolumn{2}{|c|}{$\begin{array}{l}\text { Zeta Potential } \pm \text { SD } \\
(\mathrm{mV})\end{array}$} & \multicolumn{2}{|c|}{$\begin{array}{l}\mathrm{MDD} \pm \mathrm{SD} \\
(\mathrm{nm})\end{array}$} \\
\hline & & $0 \mathrm{~h}$ & $4 \mathrm{~h}$ & $\mathrm{Oh}$ & $4 \mathrm{~h}$ & $\mathbf{O h}$ & $4 \mathrm{~h}$ & $\mathrm{Oh}$ & $4 \mathrm{~h}$ \\
\hline PN1 & $1: 1$ & $6.24 \pm 0.01$ & $6.24 \pm 0.01$ & $607 \pm 3$ & $601 \pm 5$ & $-7.26 \pm 0.47$ & $-8.22 \pm 0.35$ & $212.9 \pm 2.8$ & $212.7 \pm 2.7$ \\
\hline PN1 & $2: 1$ & $6.04 \pm 0.01$ & $6.04 \pm 0.00$ & $494 \pm 3$ & $495 \pm 3$ & $-5.72 \pm 0.73$ & $-5.54 \pm 0.23$ & $218.7 \pm 2.3$ & $210.0 \pm 3.3$ * \\
\hline PN2 & $1: 1$ & $6.22 \pm 0.01$ & $6.22 \pm 0.00$ & $633 \pm 3$ & $629 \pm 3$ & $-6.49 \pm 0.20$ & $-7.07 \pm 0.61$ & $216.4 \pm 2.7$ & $214.0 \pm 1.4$ \\
\hline PN2 & $2: 1$ & $6.03 \pm 0.01$ & $6.03 \pm 0.01$ & $511 \pm 2$ & $510 \pm 1$ & $-3.63 \pm 0.51$ & $-4.43 \pm 0.09$ & $213.4 \pm 0.8$ & $212.4 \pm 2.7$ \\
\hline PN3 & $1: 1$ & $6.14 \pm 0.00$ & $6.14 \pm 0.00$ & $701 \pm 2$ & $712 \pm 3$ & $-5.87 \pm 0.16$ & $-7.04 \pm 0.42$ & $215.0 \pm 2.5$ & $212.8 \pm 1.7$ \\
\hline PN3 & $2: 1$ & $6.00 \pm 0.01$ & $6.00 \pm 0.01$ & $548 \pm 7$ & $545 \pm 3$ & $-3.31 \pm 0.27$ & $-3.41 \pm 0.31$ & $214.3 \pm 2.5$ & $212.4 \pm 1.7$ \\
\hline PN4 & $1: 1$ & $6.09 \pm 0.01$ & $6.09 \pm 0.01$ & $724 \pm 2$ & $725 \pm 1$ & $-4.86 \pm 0.31$ & $-5.41 \pm 0.51$ & $214.5 \pm 3.7$ & $214.4 \pm 2.0$ \\
\hline PN4 & $2: 1$ & $6.00 \pm 0.01$ & $5.93 \pm 0.02 *$ & $554 \pm 4$ & $555 \pm 3$ & $-2.50 \pm 0.15$ & $-2.44 \pm 0.54$ & $215.3 \pm 0.6$ & $212.5 \pm 2.2$ \\
\hline PN5 & $1: 1$ & $6.32 \pm 0.01$ & $6.31 \pm 0.01$ & $601 \pm 1$ & $608 \pm 1$ & $-9.02 \pm 0.80$ & $-10.26 \pm 0.33$ & $214.3 \pm 0.9$ & $211.0 \pm 0.6$ \\
\hline PN5 & $2: 1$ & $6.15 \pm 0.01$ & $5.95 \pm 0.01 *$ & $493 \pm 6$ & $492 \pm 3$ & $-4.91 \pm 0.60$ & $-7.27 \pm 0.09$ & $215.6 \pm 2.8$ & $209.7 \pm 1.6$ \\
\hline PN6 & $1: 1$ & $6.29 \pm 0.01$ & $6.29 \pm 0.01$ & $634 \pm 4$ & $638 \pm 5$ & $-8.46 \pm 0.48$ & $-10.31 \pm 0.55$ & $214.6 \pm 2.3$ & $213.2 \pm 3.0$ \\
\hline PN6 & $2: 1$ & $6.12 \pm 0.01$ & $5.98 \pm 0.01 *$ & $511 \pm 6$ & $511 \pm 3$ & $-4.72 \pm 0.63$ & $-6.10 \pm 0.19$ & $215.2 \pm 2.3$ & $210.2 \pm 0.8$ \\
\hline PN7 & $1: 1$ & $6.21 \pm 0.01$ & $6.12 \pm 0.00 *$ & $689 \pm 4$ & $686 \pm 1$ & $-8.91 \pm 0.62$ & $-12.80 \pm 0.56^{*}$ & $216.3 \pm 2.2$ & $214.4 \pm 2.4$ \\
\hline PN7 & $2: 1$ & $6.08 \pm 0.00$ & $5.88 \pm 0.01 *$ & $540 \pm 2$ & $547 \pm 5$ & $-7.63 \pm 0.23$ & $-10.77 \pm 0.32$ & $214.5 \pm 2.1$ & $212.4 \pm 2.4$ \\
\hline PN8 & $1: 1$ & $6.17 \pm 0.01$ & $6.10 \pm 0.00 *$ & $730 \pm 5$ & $715 \pm 2$ * & $-7.93 \pm 0.62$ & $-9.20 \pm 0.41$ & $218.6 \pm 3.1$ & $216.1 \pm 4.3$ \\
\hline PN8 & $2: 1$ & $6.04 \pm 0.02$ & $5.87 \pm 0.01 *$ & $558 \pm 1$ & $564 \pm 1$ & $-5.26 \pm 0.31$ & $-6.01 \pm 0.23$ & $216.6 \pm 4.1$ & $214.2 \pm 4.0$ \\
\hline PN9 & $1: 1$ & $6.26 \pm 0.01$ & $6.28 \pm 0.01$ & $535 \pm 5$ & $531 \pm 8$ & $-10.00 \pm 0.36$ & $-12.37 \pm 0.32$ & $215.8 \pm 2.9$ & $211.7 \pm 3.6$ \\
\hline PN9 & $2: 1$ & $6.06 \pm 0.01$ & $6.04 \pm 0.01$ & $441 \pm 6$ & $441 \pm 5$ & $-6.66 \pm 0.96$ & $-8.52 \pm 0.91$ & $214.5 \pm 3.7$ & $214.9 \pm 2.7$ \\
\hline PN10 & $1: 1$ & $6.23 \pm 0.01$ & $6.24 \pm 0.01$ & $553 \pm 1$ & $555 \pm 5$ & $-8.72 \pm 0.23$ & $-8.77 \pm 0.63$ & $217.7 \pm 4.6$ & $214.2 \pm 3.1$ \\
\hline PN10 & $2: 1$ & $6.05 \pm 0.01$ & $6.00 \pm 0.02 *$ & $453 \pm 5$ & $455 \pm 5$ & $-5.41 \pm 0.67$ & $-5.68 \pm 0.52$ & $215.0 \pm 4.4$ & $214.7 \pm 4.3$ \\
\hline PN11 & $1: 1$ & $6.06 \pm 0.01$ & $6.06 \pm 0.01$ & $634 \pm 0$ & $626 \pm 3$ & $-7.33 \pm 0.26$ & $-7.46 \pm 0.72$ & $220.6 \pm 4.0$ & $216.1 \pm 1.6$ \\
\hline PN11 & $2: 1$ & $5.90 \pm 0.00$ & $5.90 \pm 0.01$ & $503 \pm 7$ & $502 \pm 6$ & $-6.22 \pm 0.43$ & $-5.82 \pm 0.35$ & $212.5 \pm 2.2$ & $211.9 \pm 1.9$ \\
\hline PN12 & $1: 1$ & $6.13 \pm 0.01$ & $6.15 \pm 0.02$ & $654 \pm 4$ & $653 \pm 5$ & $-7.13 \pm 0.47$ & $-6.81 \pm 0.19$ & $218.4 \pm 4.7$ & $213.1 \pm 3.1$ \\
\hline PN12 & $2: 1$ & $6.03 \pm 0.01$ & $5.88 \pm 0.02 *$ & $521 \pm 4$ & $520 \pm 3$ & $-4.79 \pm 0.54$ & $-5.32 \pm 0.14$ & $214.5 \pm 3.7$ & $214.7 \pm 3.3$ \\
\hline PN13 & $1: 1$ & $6.29 \pm 0.01$ & $6.25 \pm 0.02$ & $613 \pm 4$ & $610 \pm 5$ & $-9.93 \pm 0.70$ & $-15.80 \pm 0.40 *$ & $323.8 \pm 2.7$ & $323.6 \pm 3.6$ \\
\hline PN13 & $2: 1$ & $6.08 \pm 0.01$ & $6.04 \pm 0.00$ & $497 \pm 7$ & $497 \pm 2$ & $-14.43 \pm 0.49$ & $-14.13 \pm 1.63$ & $325.7 \pm 7.0$ & $330.0 \pm 8.3$ \\
\hline PN14 & $1: 1$ & $6.26 \pm 0.01$ & $6.26 \pm 0.01$ & $628 \pm 1$ & $629 \pm 4$ & $-12.97 \pm 0.55$ & $-11.27 \pm 1.21$ & $326.5 \pm 6.4$ & $326.7 \pm 5.2$ \\
\hline PN14 & $2: 1$ & $6.06 \pm 0.01$ & $6.05 \pm 0.01$ & $503 \pm 1$ & $506 \pm 3$ & $-10.47 \pm 1.14$ & $-11.57 \pm 1.31$ & $322.4 \pm 7.0$ & $317.9 \pm 1.7$ \\
\hline PN15 & $1: 1$ & $6.13 \pm 0.01$ & $6.12 \pm 0.00$ & $681 \pm 3$ & $675 \pm 3$ & $-11.47 \pm 0.85$ & $-11.13 \pm 0.76$ & $323.9 \pm 2.2$ & $319.9 \pm 5.2$ \\
\hline PN15 & $2: 1$ & $5.99 \pm 0.01$ & $5.99 \pm 0.01$ & $537 \pm 3$ & $533 \pm 3$ & $-11.30 \pm 0.30$ & $-9.10 \pm 0.93$ & $325.5 \pm 5.0$ & $320.5 \pm 5.3$ \\
\hline PN16 & $1: 1$ & $6.13 \pm 0.01$ & $6.14 \pm 0.00$ & $723 \pm 6$ & $717 \pm 2$ & $-10.45 \pm 0.70$ & $-8.85 \pm 0.91$ & $323.4 \pm 5.4$ & $324.3 \pm 1.1$ \\
\hline PN16 & $2: 1$ & $5.99 \pm 0.01$ & $6.00 \pm 0.02$ & $563 \pm 4$ & $559 \pm 1$ & $-11.17 \pm 0.75$ & $-6.75 \pm 1.25 *$ & $321.8 \pm 4.8$ & $324.7 \pm 3.5$ \\
\hline PN17 & $1: 1$ & $6.33 \pm 0.02$ & $6.27 \pm 0.01 *$ & $624 \pm 1$ & $626 \pm 5$ & $-16.27 \pm 0.71$ & $-14.63 \pm 0.55$ & $329.0 \pm 10.6$ & $325.2 \pm 4.5$ \\
\hline PN17 & $2: 1$ & $6.17 \pm 0.02$ & $5.89 \pm 0.01 *$ & $501 \pm 6$ & $503 \pm 3$ & $-15.27 \pm 1.02$ & $-11.83 \pm 0.75$ & $328.4 \pm 1.7$ & $328.5 \pm 4.3$ \\
\hline PN18 & $1: 1$ & $6.32 \pm 0.02$ & $6.22 \pm 0.02 *$ & $602 \pm 5$ & $597 \pm 8$ & $-26.30 \pm 0.56$ & $-18.13 \pm 0.40 *$ & $326.4 \pm 4.1$ & $332.7 \pm 7.2$ \\
\hline PN18 & $2: 1$ & $6.14 \pm 0.01$ & $5.82 \pm 0.02 *$ & $484 \pm 1$ & $484 \pm 5$ & $-21.03 \pm 2.06$ & $-12.53 \pm 0.7 *$ & $325.8 \pm 6.0$ & $329.5 \pm 8.3$ \\
\hline
\end{tabular}

$*$ significance $p<0.05$ differences between value of $t=4 \mathrm{~h}$ and $t=0 \mathrm{~h}$. 
The zeta potential of the PN admixtures was between $-22.47 \pm 0.81 \mathrm{mV}$ and $-8.38 \pm 0.15 \mathrm{mV}$ (Table 2). The lowest values were observed for PN18, and the highest for PN4. The highest zeta potential values for samples with the CF were observed for CF-PN4 at the ratio 2:1 (v/v). The lowest zeta potential values were observed for CF-PN18 at a 1:1 (v/v) ratio (Table 3).

The MDD of PN1-PN18 ranged from $216.5 \pm 2.4 \mathrm{~nm}$ to $338.8 \pm 3.4 \mathrm{~nm}$ (Table 2). The addition of the CF caused a slight shift of this range toward lower values (from $212.5 \pm 2.2 \mathrm{~nm}$ to $329.0 \pm 10.6 \mathrm{~nm}$ ). The addition of the CF to the PN admixtures decreased the MDD for all samples except CF-PN11 and CF-PN17, at the ratio 1:1 $(v / v)$, for which no change or a slight increase in the MDD was observed (Table 3).

All PN admixtures were evaluated visually (against white and black backgrounds) upon preparation, after the CF addition and four hours later. The PN admixtures without any CF content were white homogeneous oil-in-water emulsions and showed no signs of reversible (sedimentation, creaming) or irreversible (coalescence and flocculation) degradation of the lipid emulsion during four hours of storage. The addition of the CF to the PN admixtures did not cause any color change or visible degradation of the lipid emulsion immediately after the addition, whereas, after four hours of storage, a sedimenting flocculent precipitate was observed in the CF-(PN5-PN8) and CF-(PN17-PN18) at the ratio $1: 1(v / v)$ and in all $\mathrm{CF}-\mathrm{PN}$ at the ratio $2: 1(v / v)$.

The precipitate was dried, and spectra were plotted, using the KBr tablets method. The spectra of precipitate and reference sample of CF are presented on Figure 1. The calculated purity factor was 0.9552 , indicating high spectral matching. The purity graph shows the correlation curve of the intensities of the source spectrum with respect to those of the reference spectrum (Figure 2).

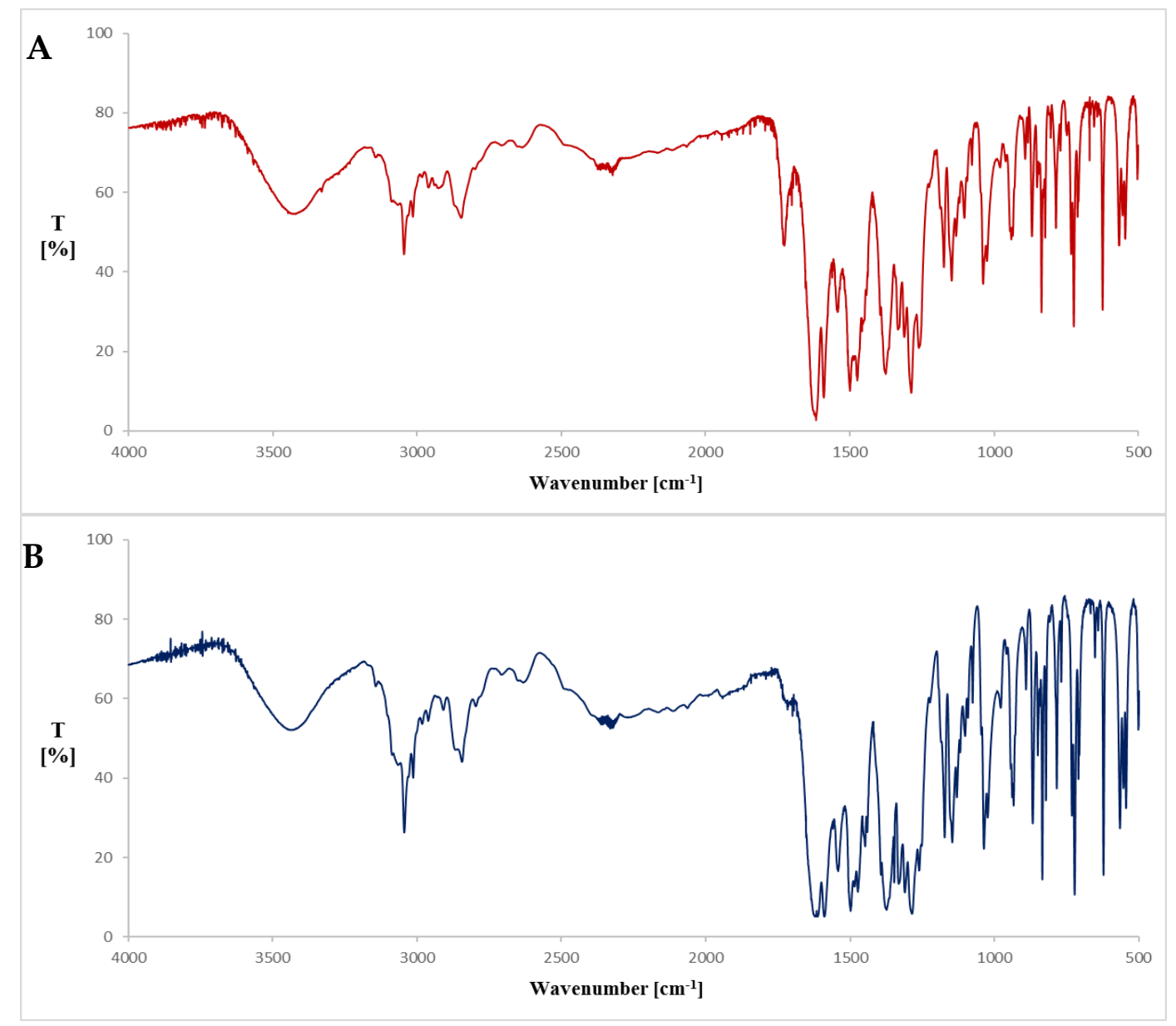

Figure 1. FT-IR spectra of precipitate (A) and reference sample of CF (B). 


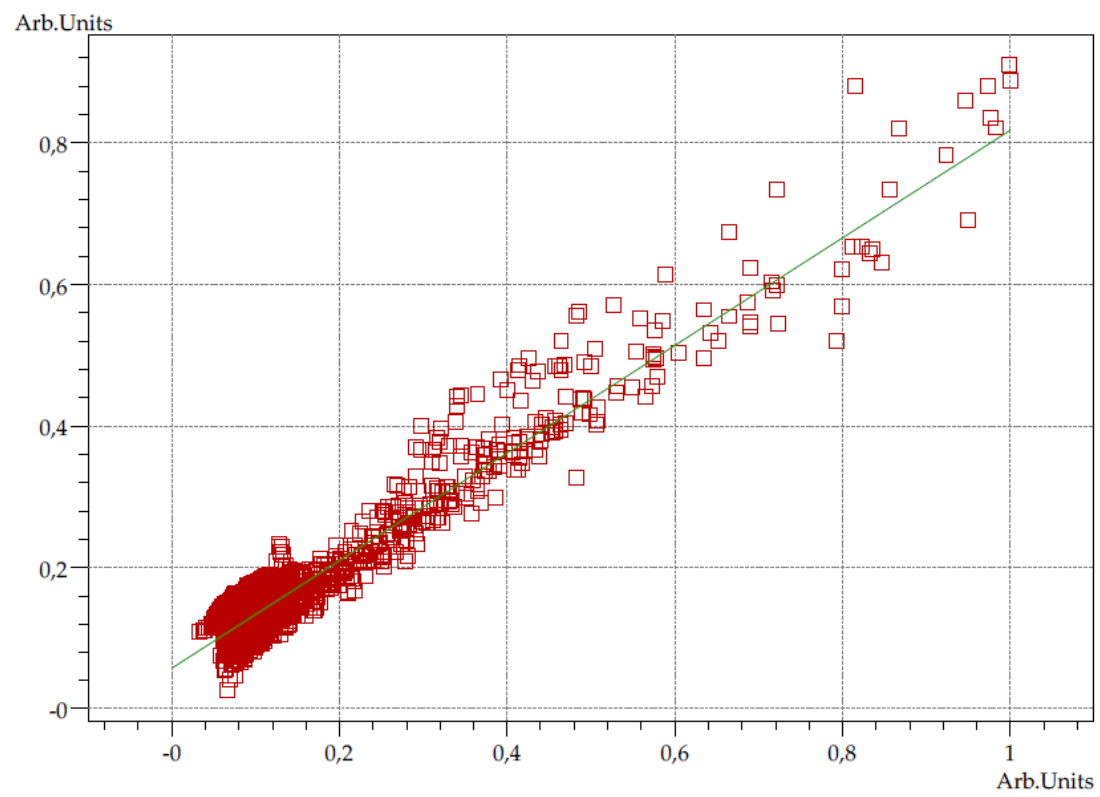

Figure 2. Correlation curve of the intensities of the precipitate spectrum and the reference spectrum.

Table 4 shows characteristic bands of the precipitate and the reference samples. The stretching vibration at $3436.21 \mathrm{~cm}^{-1}$ is attributed to the $\mathrm{OH}$ in the carboxylic group. The absorption band at $1621.67 \mathrm{~cm}^{-1}$ is associated with the symmetric stretching of $\mathrm{C}=\mathrm{O}$ of pyridone moieties. Stretching band assigned to the $C=C$ and $C-N$ are seen at $1587.91 \mathrm{~cm}^{-1}$ and $1284.60 \mathrm{~cm}^{-1}$, respectively. The absorption band at $1036.26 \mathrm{~cm}^{-1}$ is due to the $\mathrm{C}-\mathrm{F}$ stretching vibration, while the vibration at $722.34 \mathrm{~cm}^{-1}$ indicates the absorption peak of secondary amine $(-\mathrm{NH})$.

Table 4. Characteristic bands of precipitate and reference sample in FT-IR spectra.

\begin{tabular}{|c|c|c|}
\hline Precipitate & Reference Sample & Peak Assignment \\
\hline \multicolumn{2}{|c|}{ Wavenumbers $\left(\mathrm{cm}^{-1}\right)$} & \\
\hline 3436.21 & 3444.15 & -OH stretching vibration \\
\hline 1621.67 & 1616.36 & $\mathrm{C}=\mathrm{O}$ stretching vibration \\
\hline 1587.91 & 1592.21 & $\mathrm{C}=\mathrm{C}$ stretching vibration \\
\hline 1284.60 & 1282.67 & $\mathrm{C}-\mathrm{N}$ stretching vibration \\
\hline 1036.26 & 1035.78 & C-F stretching vibration \\
\hline 722.34 & 722.34 & -NH vibration \\
\hline
\end{tabular}

\section{Discussion}

The PN admixtures to be studied were prepared at a volume of $1800 \mathrm{~mL}$ each, with a glucose content of $450 \mathrm{~mL}$. The PN1-PN12 admixtures contained Lipofundin MCT/LCT 20\%. The PN13-PN18 admixtures differed from PN1-PN6 only in the lipid emulsion used (Smoflipid 20\%). Formulations PN1-PN8 and PN13-PN18 were characterized by a high content of monopositive ions in comparison with a low content of such cations in formulations PN9-PN12. The PN1-PN4 and PN9-PN16 formulations contained a greater amount of divalent cations (magnesium and calcium). In addition, the molar ratio of formulations with a higher content of divalent cations was 1:1, and those with a lower content of magnesium and calcium ions had a molar ratio of 2:1.

The sedimentation observed in all samples containing the CF at a volume ratio of 2:1 probably resulted from a high CF concentration in the samples $(1.33 \mathrm{mg} / \mathrm{mL})$ and the acid-base balance manifested by the $\mathrm{pH}$ of the CF-PN admixtures of about 6, with a possible effect on CF solubility. According to the Henderson-Hasselbalch equation, when the $\mathrm{pH}$ of the solution exceeds the $\mathrm{pKa}$ of the functional group that can be protonated, the deprotonated form dominates. Thus, as the $\mathrm{pH}$ increases, the 
basic functional groups become non-ionized and less soluble in water, while acidic functional groups become ionized and more soluble in water [12]. CF has both a carboxyl group ( $\mathrm{pKa} \approx 6.1$ ), as well as the piperazine basic group ( $\mathrm{pKa} \approx 8.7$ ), which causes that this drug has a $\mathrm{pH}$-dependent solubility. Depending on the $\mathrm{pH}$, the $\mathrm{CF}$ can occur in the following ionic forms: cationic at acidic $\mathrm{pH}$, zwitterionic at $\mathrm{pH}$ values comprising $\mathrm{pKa}$, and an anionic at basic $\mathrm{pH}$ [23]. $\mathrm{CF}$ is poorly water-soluble drug and exhibits a U-shaped $\mathrm{pH}$-solubility profile, with high solubility at $\mathrm{pH}$ values below 5 and above 10, and minimum solubility near the isoelectric point, which is close to neutral $\mathrm{pH}$ [24]. At $\mathrm{pH} \mathrm{7.4,} \mathrm{the} \mathrm{majority}$ of $\mathrm{CF}$ molecules exist in the form of zwitterions with a global neutral charge, and it is the least soluble. In contrast, at $\mathrm{pH} 3$ the solubility of $\mathrm{CF}$ increases significantly. At $\mathrm{pH} 5$, about $90 \%$ of $\mathrm{CF}$ is transformed into a cationic form with a greater solubility than the zwitterion form, and its solubility increases with the $\mathrm{pH}$ lowering [25]. At the $\mathrm{pH}$ characteristic for mixtures of $\mathrm{CF}$ and $\mathrm{PN}$ admixtures (5.82-6.33), we predicted that the solubility of CF would still be low.

In the case of CF-PN admixtures at a 1:1 volume ratio (CF concentration $=1 \mathrm{mg} / \mathrm{mL}$ ), the presence or absence of precipitation was probably also caused by the influence of cations present in the PN admixture formulations: monovalent (sodium and potassium) and divalent (calcium and magnesium) ions. In the presence of metal cations (except magnesium ions), CF in an acidic environment forms well-soluble complexes, while, in the presence of magnesium sulfate, the solubility of CF slightly rises as the amount of magnesium sulfate increases, followed by a gradual decrease. At higher concentrations of magnesium sulfate, precipitation has been observed [26]. Turel et al. [27] showed that $\mathrm{CF}$ forms adducts with magnesium sulfate, in which magnesium is not bound to the drug molecule but is coordinated by six water molecules to form aquacation $\left[\mathrm{Mg}\left(\mathrm{H}_{2} \mathrm{O}\right)_{6}\right]^{2+}$. In our study, for the $\mathrm{CF}-\mathrm{PN}$ admixtures at the volume ratio 1:1 precipitation was observed in formulations with lower concentrations of magnesium and calcium ions in which the molar ratio of magnesium to calcium ions was 2:1. This may be associated with the formation of a magnesium adduct with water molecules, which results in reduced CF solubility and precipitation of CF zwitterions. To confirm the identity of CF in precipitate, we performed FT-IR analysis. The measured spectrum of precipitate presented similar absorption bands to the spectrum of the reference sample and CF spectrum showed in the literature [28]. The spectra were characterized by the high matching coefficient, expressed as a purity factor equal to 0.9552 . The spectrum of precipitate presented the characteristic bands for CF in the fingerprint region. The sharp peak at $1724.37 \mathrm{~cm}^{-1}$ observed in the precipitate and less formed in the reference sample could be due to the disruptive interference of the solvent.

Regarding the CF-PN admixtures for which no precipitation was observed, the molar ratio of magnesium to calcium ions was 1:1 (v/v), which was probably associated with a greater affinity of calcium ions for CF molecules and the formation of well-soluble complexes, more hydrophilic than CF. Figure 3 presents relationships between the $\mathrm{pH}$ of the $\mathrm{PN}$ admixtures, the molar ratio of magnesium and calcium ions, and observations concerning precipitation.

In this study, the presence or absence of precipitation did not correlate with the physical parameters of the CF-PN admixtures, which did not exceed the pharmacopeial value (MDD $>500 \mathrm{~nm}$ ) [22]. It should be noted that a sole reliance on the physical parameters of CF-PN admixtures in clinical practice may endanger the patient's health by administering a drug of inadequate quality.

The MDD of the lipid emulsion did not increase in the CF-PN admixtures for which precipitation was observed. This was due to the sedimentation of the precipitate to the bottom of the measuring cuvette, which did not interfere with the measurement of this parameter. The ZetaSizer Nano ZS used in the tests to measure the distribution of particle sizes for stable emulsions and suspensions ranging in size from $0.3 \mathrm{~nm}$ to $10 \mu \mathrm{m}$. In this method, the dispersion of nanoparticles is illuminated by a laser beam. The laser light is scattered and next captured by the detector. The speed of particles is measured on the basis of Brownian motion and then converted to particle-size distribution, using the Stokes-Einstein equation. Therefore, in the case of precipitation of insoluble particles, visual and/or microscopic assessment is necessary, as the measurement of the particle-size distribution alone can cause false positive results. 


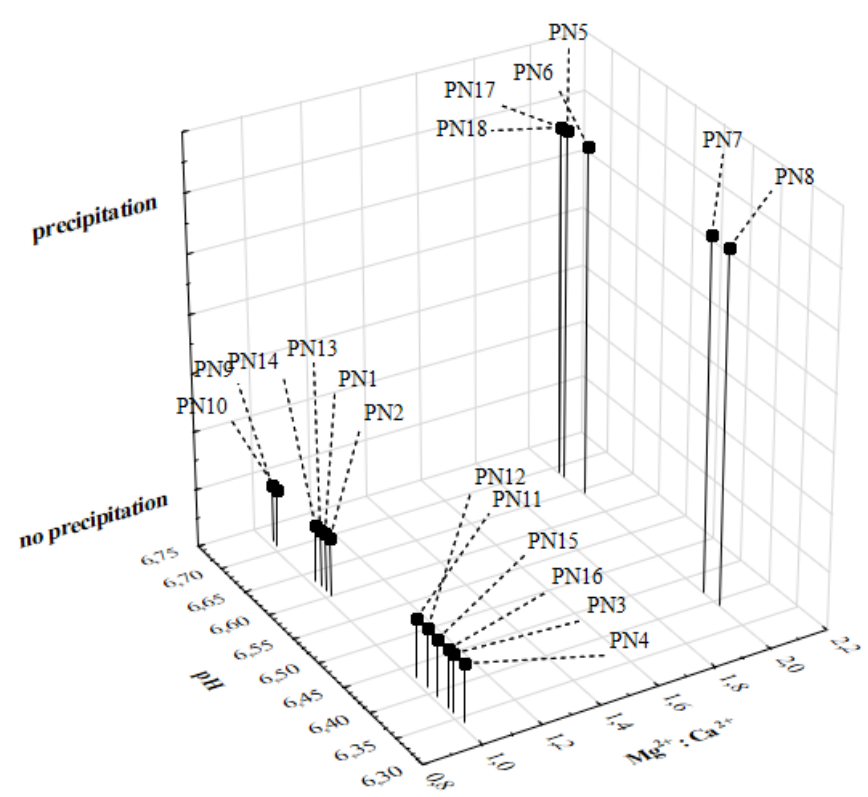

Figure 3. Relationships between the $\mathrm{pH}$ of the $\mathrm{PN}$ admixtures, the molar ratio of magnesium and calcium ions, and observations concerning precipitation.

The lack of compatibility between CF and PN admixtures containing only lipid emulsion and glucose was observed by Omotani et al. [29] immediately after sample preparation. The authors mixed a $5 \%$ glucose solution with a $20 \%$ Intralipos fat emulsion ( $100 \%$ soybean oil) with CF at a volume ratio of 33:10:40, and then counted the number of large insoluble particles by using the light obscuration method upon sample preparation and after 1,3,6, 12, and $24 \mathrm{~h}$ of storage. The results indicated particles with a diameter ranging from 25 to $50 \mu \mathrm{m}$ directly after sample preparation. The occurrence of above $0.05 \%$ particles exceeding $5 \mu \mathrm{m}$ in diameter disqualifies the CF-PN admixture from administration [22].

\section{Limitations}

The aim of our study was to evaluate the compatibility of CF with selected PN admixtures. Determining the mechanism of observed interaction would be very interesting but also very difficult to implement. It should be emphasized that the PN admixture is one of the most complex drugs used in modern medicine and pharmacy. By analyzing its composition, more than 30 substances can be detected that jointly affect the drug combined with the PN admixture. Explanation of the mechanism of formation of $\mathrm{CF}$ precipitation would require the preparation of another several dozen model PN admixtures with increasing ion concentrations, their different molar ratios, and different contents of other components of the PN admixture affecting such parameters as even $\mathrm{pH}$. It was also not advisable to prepare simpler systems, e.g., without a lipid emulsion or amino acid solution, because each of these components may indirectly affect the solubility of $\mathrm{CF}$, e.g., by changing the $\mathrm{pH}$. That is why we determined the compatibility of CF with selected PN admixtures used in clinical practice. Our hypothesis concerning the impact of $\mathrm{pH}$ and molar ratios of selected ions was an attempt to find factors responsible for the interaction and was not in itself an explanation of the mechanism of observed interactions.

\section{Conclusions}

The compatibility tests showed that the addition of the CF to the PN admixtures did not cause any color change or sign of destabilization in the fat emulsion. However, precipitation was observed in formulations containing higher CF concentrations and, in the case of lower CF concentrations, in formulations containing magnesium and calcium ions at a molar ratio of 2:1. Due to the inconclusive findings regarding compatibility between the CF and the PN admixtures, it is advisable that the 
administration of CF-PN admixtures via the Y-site should be avoided or performed only with PN admixtures for which compatibility has been confirmed and the CF concentration in samples is $1 \mathrm{mg} / \mathrm{mL}$ at a molar ratio of magnesium to calcium ions of 1:1.

Author Contributions: Conceptualization, A.G. and M.S.; methodology, M.S. and A.G.; formal analysis, A.G.; investigation, A.G. and K.D.; resources, K.D.; writing-original draft preparation, A.G. and M.S. writing-review and editing, K.D. and A.J.; supervision, A.J. All authors have read and agreed to the published version of the manuscript.

Funding: This research was funded by National Science Centre, Poland, grant SONATA no. 2015/17/D/NZ7/00792.

Conflicts of Interest: The authors declare no conflict of interest.

\section{References}

1. Vincent, J.L.; Rello, J.; Marshall, J.; Silva, E.; Anzueto, A.; Martin, C.D.; Moreno, R.; Lipman, J.; Gomersall, C.; Sakr, Y.; et al. International study of the prevalence and outcomes of infection in intensive care units. JAMA 2009, 302, 2323-2329. [CrossRef] [PubMed]

2. Van Zanten, A.R.; Polderman, K.H.; van Geijlswijk, I.M.; van der Meer, G.Y.; Schouten, M.A.; Girbes, A.R. Ciprofloxacin pharmacokinetics in critically ill patients: A prospective cohort study. J. Crit. Care 2008, 23, 422-430. [CrossRef] [PubMed]

3. Taxis, K.; Barber, N. Ethnographic study of incidence and severity of intravenous drug errors. BMJ 2003, 326, 684-688. [CrossRef] [PubMed]

4. Taxis, K.; Barber, N. Incidence and severity of intravenous drug errors in a German hospital. Eur. J. Clin. Pharmacol. 2004, 59, 815-817. [PubMed]

5. Taxis, K.; Barber, N. Causes of intravenous medication errors: An ethnographic study. Qual. Saf. Health Care 2003, 12, 343-348. [CrossRef]

6. Allen, L.V.; Levinson, R.S.; Phisutsinthop, D. Compatibility of various admixtures with secondary additives at Y-injection sites of intravenous administration sets. Am. J. Hosp. Pharm. 1977, 34, 939-943. [CrossRef]

7. Staven, V.; Iqbal, H.; Wang, S.; Grønlie, I.; Tho, I. Physical compatibility of total parenteral nutrition and drugs in Y-site administration to children from neonates to adolescents. J. Pharm. Pharmacol. 2017, 69, 448-462. [CrossRef]

8. Watson, D. Piggyback compatibility of antibiotics with pediatric parenteral nutrition solutions. J. Parenter. Enter. 1985, 9, 220-224. [CrossRef]

9. Stawny, M.; Olijarczyk, R.; Jaroszkiewicz, E.; Jelińska, A. Pharmaceutical point of view on parenteral nutrition. Sci. World J. 2013, 2013, 415310. [CrossRef]

10. Slattery, E.; Rumore, M.M.; Douglas, J.S.; Seres, D.S. 3-in-1 vs 2-in-1 parenteral nutrition in adults: A review. Nutr. Clin. Pract. 2014, 29, 631-635. [CrossRef]

11. Kanji, S.; Lam, J.; Johanson, C.; Singh, A.; Goddard, R.; Fairbairn, J.; Lloyd, T.; Monsour, D.; Kakal, J. Systematic review of physical and chemical compatibility of commonly used medications administered by continuous infusion in intensive care units. Crit. Care Med. 2010, 38, 1890-1898. [CrossRef] [PubMed]

12. Newton, D.W. Drug incompatibility chemistry. Am. J. Health Syst. Pharm. 2009, 66, 348-357. [CrossRef] [PubMed]

13. Hill, S.E.; Heldman, L.S.; Goo, E.D.; Whippo, P.E.; Perkinson, J.C. Fatal microvascular pulmonary emboli from precipitation of a total nutrient admixture solution. J. Parenter. Enter. Nutr. 1996, 20, 81-87. [CrossRef] [PubMed]

14. Bradley, J.S.; Wassel, R.T.; Lee, L.; Nambiar, S. Intravenous ceftriaxone and calcium in the neonate: Assessing the risk for cardiopulmonary adverse events. Pediatrics 2009, 123, 609-613. [CrossRef]

15. Driscoll, D.F.; Ling, P.R.; Bistrian, B.R. Pathological consequences to reticuloendothelial system organs following infusion of unstable all-in-one mixtures in rats. Clin. Nutr. 2006, 25, 842-850. [CrossRef]

16. Driscoll, D.F.; Nehne, J.; Peterss, H.; Klutsch, K.; Bistrian, B.R.; Niemann, W. Physical assessments of lipid injectable emulsions via microscopy: A comparison to methods proposed in united states pharmacopeia chapter 729. Int. J. Pharm. Compd. 2006, 10, 309-315.

17. Driscoll, D.F.; Ling, P.R.; Silvestri, A.P.; Bistrian, B.R. Fine vs. coarse complete all-in-one admixture infusions over 96 hours in rats: Fat globule size and hepatic function. Clin. Nutr. 2008, 27, 889-894. [CrossRef] 
18. Trissel, L.A.; Gilbert, D.L.; Martinez, J.F.; Baker, M.B.; Walter, W.V.; Mirtallo, J.M. Compatibility of parenteral nutrient solutions with selected drugs during simulated Y-site administration. Am. J. Hosp. Pharm. 1997, 54, 1295-1300. [CrossRef]

19. Trissel, L.A.; Gilbert, D.L.; Martinez, J.F.; Baker, M.B.; Walter, W.V.; Mirtallo, J.M. Compatibility of medications with 3-in-1 parenteral nutrition admixtures. J. Parenter. Enter. Nutr. 1999, 23, 67-74. [CrossRef]

20. European Directorate for Quality in Medicines and Healthcare (EDQM). Chromatographic separation techniques. In European Pharmacopoeia 9.0; EDQM: Strasburg, France, 2017; Chapter 2.2.46; pp. 74-80.

21. Stawny, M.; Gostyńska, A.; Dettlaff, K.; Jelińska, A.; Główka, E.; Ogrodowczyk, M. Effect of lipid emulsion on stability of ampicillin in total parenteral nutrition. Nutrients 2019, 11, 559. [CrossRef]

22. The United States Pharmacopeia and National Formulary, 38th ed.; United States Pharmacopeial Convention: Rockville, MD, USA, 2015.

23. Völgyi, G.; Ruiz, R.; Box, K.; Comer, J.; Bosch, E.; Takács-Novák, K. Potentiometric and spectrophotometric pKa determination of water-insoluble compounds: Validation study in a new cosolvent system. Anal. Chim. Acta 2007, 583, 418-428. [CrossRef] [PubMed]

24. Breda, S.A.; Jimenez-Kairuz, A.F.; Manzo, R.H.; Olivera, M.E. Solubility behavior and biopharmaceutical classification of novel high-solubility ciprofloxacin and norfloxacin pharmaceutical derivatives. Int. J. Pharm. 2009, 17, 106-113. [CrossRef] [PubMed]

25. Stojković, A.; Tajber, L.; Paluch, K.J.; Djurić, Z.; Parojčić, J. Corrigan OI. Biopharmaceutical characterization of ciprofloxacin-metallic ion interactions: Comparative study into the effect of aluminium, calcium, zinc and iron on drug solubility and dissolution. Acta Pharm. 2014, 64, 77-88. [CrossRef] [PubMed]

26. Eboka, C.J.; Okeri, H.A. Aqueous solubility of ciprofloxacin in the presence of metal cations. Trop. J. Pharm. Res. 2005, 4, 349-354. [CrossRef]

27. Turel, I.; Leban, I.; Zupancic, M.; Bukovec, P.; Gruber, K. An adduct of magnesium sulfate with a member of the quinolone family (Ciprofloxacin). Acta Crystallogr. 1996, 52, 2443-2445. [CrossRef]

28. Japanese Pharmacopoeia, 17th ed.; Pharmaceuticals and Medical Devices Agency: Tokyo, Japan, 2016.

29. Omotani, S.; Aoe, M.; Esaki, S.; Nagai, K.; Hatsuda, Y.; Mukai, J.; Teramachi, H.; Myotoku, M. Compatibility of intravenous fat emulsion with antibiotics for secondary piggyback infusion. Ann. Nutr. Metab. 2018, 73, 227-233. [CrossRef] [PubMed]

(C) 2019 by the authors. Licensee MDPI, Basel, Switzerland. This article is an open access article distributed under the terms and conditions of the Creative Commons Attribution (CC BY) license (http://creativecommons.org/licenses/by/4.0/). 